\title{
Genetic Parameters for Female Fertility Traits and a Fertility Index in Spanish Dairy Cattle
}

\section{O. González-Recio and R. Alenda}

Departamento de Producción Animal, E.T.S.I. Agrónomos - Universidad Politécnica, Ciudad Universitaria s/n, Universidad Politécnica de Madrid, 28040 Madrid, Spain

\begin{abstract}
Genetic correlations among female fertility traits (linear and binary) were estimated using 225,085 artificial insemination records from 120,713 lactations on 63,160 Holstein cows. Fertility traits were: calving interval, days open, a linear transformation of days open, days to first insemination, interval between first and last insemination, number of inseminations per service period, pregnancy within 56 and $90 \mathrm{~d}$ after first insemination, and success in first insemination. A bivariate animal model was implemented using Bayesian methods in the case of binary traits. Low heritabilities $(0.02$ to 0.06 ) were estimated for these fertility traits. Strong genetic correlations (0.89 to 0.99 ) were found among traits, except for days to first service, where the genetic correlation with other fertility traits ranged from -0.52 to -0.18 for binary traits, and from 0.50 to 0.82 for days to first service, calving interval, and days open. Four fertility indices were proposed utilizing information from insemination records; these indices combined one indicator of the beginning of the service period and one indicator of conception rate. Two additional indices used information from the milk-recording scheme, including calving interval and a linear transformation of days open. The fertility index composed of days to first service and pregnancy within $56 \mathrm{~d}$ achieved the highest genetic gain for reducing fertility cost, reducing days to first service, and reducing the number of inseminations per lactation $(\$ 8.60,-1.31 \mathrm{~d}$, and $-0.03 \mathrm{AI}$, respectively). This index achieved at least $15 \%$ higher genetic gain than obtained from indices with information from the milk recording scheme only (calving interval and days open).
\end{abstract}

(Key words: female fertility, selection index, recording scheme)

Abbreviation key: $\mathbf{C I}=$ calving interval, $\mathbf{P R}=$ pregnancy rate, $\mathbf{D F S}=$ days to first service, $\mathbf{D O}=$ days

Received February 16, 2005

Accepted April 22, 2005.

Corresponding author: Oscar González-Recio; e-mail: ogrecio@ pan.etsia.upm.es. open, IFL = interval between first and last insemination, INS = number of inseminations per service period, $\mathbf{P}=$ pregnancy within $56 \mathrm{~d}$ (P56) or $90 \mathrm{~d}$ (P90) after first insemination, $\mathbf{S F}=$ success in first insemination.

\section{INTRODUCTION}

The dairy industry demands improvement in functional traits (udder health, locomotion, calving ease, fertility). Importance of fertility in dairy cattle is well known, both in functionality and farm economy (Groen et al., 1997; González-Recio et al., 2004; Pryce et al., 2004). According to Groen et al. (1997) and De Jong and Harbers (2001), proper female fertility was defined as showing heat in timely manner and becoming pregnant with a minimum number of inseminations. Reducing days to first service (DFS) and number of inseminations per lactation (INS) would lead to cows with fertile heats early in lactation that become pregnant when dairy producers desire, thereby reducing costs of semen, hormonal treatments and veterinary fees. These traits should be considered in the breeding goal. However, there is no consensus of which traits should be included in the fertility index. Calving interval (CI), days open (DO), interval between first and last insemination (IFL), INS, DFS, success in first insemination (SF), and nonreturn rates are traits that have been integrated in different fertility indices (Interbull, 2004). Genetic evaluations across countries for fertility will be available in the near future (Wall et al., 2003). Hence, recommendations should be made regarding traits that should be included in a fertility index to minimize costs due to infertility.

Fertility traits present several difficulties with respect to statistical analysis. Methodological problems arise in (co)variance estimation for binary traits (e.g., nonreturn rates of SF), because many assumptions of linear models are violated. Bayesian methodology is often the best path to deal with such problems (Thompson, 1979; Gianola, 1982). Nonetheless, some problems remain. For example, when every observation within a given level of a fixed effect falls within the same category (i.e., all 0 or all 1), extreme category problems occur, and these can lead to bias in (co)variance estima- 
tion. Also, extremely high or low incidence rates and a low number of observations per fixed effect subclass can lead to severe bias (Moreno et al., 1997). Several authors cited the sire model as preferable (e.g., Hoeschele and Tier, 1995) because of these problems. However, accuracy of EBV could be increased using an animal model. An animal model could be applied to categorical traits by considering extended contemporary groups and by treating the herd-year effect as random, thereby reducing problems due to data structure, although at the expense of higher computer resources.

Another problem arises from data recording organizations. Calving interval and DO can be calculated from milk recording data. The remaining traits require insemination or pregnancy examination records, and these data are not recorded in many countries due to the lack of a suitable recording program. Advantages of recording insemination data should be quantified.

The objectives of this study were to estimate genetic (co)variances between fertility traits using linear and threshold animal models, and to determine which traits should be included in a selection index to reduce fertility costs. Another aim was to quantify the economic advantages of incorporating traits from an insemination recording system, in addition to traits from the milk recording scheme, to improve fertility and reduce reproductive costs.

\section{MATERIALS AND METHODS}

\section{Data}

Data were provided by the regional Holstein associations from the Basque and Navarra Spanish Autonomous regions. Milk yield data included records from 1988 through September 2003, and reproductive data included insemination records from 1987 to December 2001. Only cows with both milk and reproductive records were considered. A minimum of 100 DIM and $1000 \mathrm{~kg}$ of milk yield per lactation were required. Gestation period was considered to be $282 \mathrm{~d}$ with an interval of $\pm 10 \mathrm{~d}$ to consider estrus period around this mean. Restrictions and rules for validation were applied to ensure the quality of reproductive data.

Rules for validating insemination data. The following editing rules were considered according to González-Recio et al. (2004):

1. Natural services, embryo transfers, and AI during the gestation period were omitted.

2. Artificial inseminations before 1993 were eliminated to avoid errors at the beginning of the reproductive recording scheme.
3. Success in first insemination was defined as ' 1 ' if the result of the first insemination was positive (gestation) and ' 0 ' otherwise.

4. Pregnancy with $56 \mathrm{~d}(\mathbf{P 5 6})$ and $90 \mathrm{~d}$ (P90) were defined as ' 1 ' if the successful insemination date was within 56 or $90 \mathrm{~d}$, respectively, after the first insemination. Otherwise, P56 (P90) was defined as ' 0 '.

5. Days from calving to first insemination were recorded as DFS. Lactations were omitted if DFS was lower than $25 \mathrm{~d}$, higher than $160 \mathrm{~d}$, or unknown.

6. Number of inseminations per service period was recorded as the number of AI from d 25 to 330 after calving. If there was no AI during that period, INS was considered a missing value.

7. Herds with an average $<1.5$ INS per cow or $>3.5$ INS per cow were eliminated.

8. Days from calving to successful AI date were recorded as DO. This trait was missing when positive gestation diagnostic was not registered. Records with DO longer than $330 \mathrm{~d}$ were eliminated.

9. The linear transformation described by Kuhn et al. (2004), was used to calculate cow pregnancy rate (PR) from DO as PR $=0.25 \times(233-\mathrm{DO})$. The PR was a missing value when $\mathrm{DO}$ was not registered.

10. Interval from first to last insemination was recorded as days from first to successful insemination date. If positive gestation was not recorded, it was a missing value.

11. Successive calving dates had to range from 300 to $600 \mathrm{~d}$. If the following calving date was not available, CI was considered a missing value. Otherwise, lactation and insemination records were not considered.

12. Cows with first calving before 18 or after 40 mo of age were excluded.

Limits were required for DFS, INS, DO, and CI to not include in the analysis records or cows with serious problems other than fertility, such as diseases that could affect reproductive ability. Contemporary groups were required to have at least 5 records to be included in statistical analysis (Ugarte et al., 1992). The data editing procedure reduced the data set to 120,713 lactation records and 225,085 insemination records from 63,160 lactating cows. The pedigree file included 91,770 animals.

\section{Estimation of Genetic Parameters}

Linear traits. Restricted maximum likelihood method was used to estimate (co)variance components. Statistical models were: 


$$
\begin{aligned}
\mathrm{y}_{\mathrm{jklmn}}=\mu & +\mathrm{DFS}_{\mathrm{jklmn}}+\mathbf{L} \mathbf{A}_{\mathrm{j}}+\mathbf{M}_{\mathrm{k}}+\mathbf{H Y} \mathbf{Y}_{1} \\
& +\mathbf{p}_{\mathrm{m}}+\mathbf{a}_{\mathrm{n}}+\mathrm{e}_{\mathrm{jklmn}} \\
\mathrm{y}_{\mathrm{jklmn}} & =\mu+\mathbf{L} \mathbf{A}_{\mathrm{j}}+\mathbf{M}_{\mathrm{k}}+\mathbf{H Y} \mathbf{Y}_{1} \\
& +\mathbf{p}_{\mathrm{m}}+\mathbf{a}_{\mathrm{n}}+\mathrm{e}_{\mathrm{jklmn}}
\end{aligned}
$$

where $\mathrm{y}_{\mathrm{jklmn}}$ was the trait of interest, $\mathrm{DFS}_{\mathrm{jklmn}}$ was days to first service as covariate, $\mathbf{L} \mathbf{A}_{\mathrm{j}}$ was a fixed effect of lactation-age at calving, $\mathbf{M}_{\mathrm{k}}$ was a fixed effect of calendar month at calving, $\mathbf{H Y}_{1}$ was a fixed effect of herdyear at calving, $\mathbf{p}_{\mathrm{m}}$ was a random permanent effect, $\mathbf{a}_{\mathrm{n}}$ was an animal genetic effect, and $e_{j k l m n}$ was a random residual term. Model [1] was applied to the following traits: INS and IFL. Model [2] was applied to DFS, PR, DO, and CI. Bivariate analyses were implemented using the VCE (ver. 4.2.5) software (Groeneveld and García-Cortés, 1998).

Binary traits. Bayesian methodology was used to estimate (co)variance components between binary and linear traits. A threshold-liability model (Gianola, 1982) was implemented for analyzing the binary traits (P56, P90, and SF). The threshold model postulates an underlying continuous distribution for a random variable named liability $(\lambda)$. Variance of that distribution were set to arbitrary values: $\lambda \sim \mathrm{N}(\mu, 1)$. This liability is less or greater than a threshold $(t)$ depending on the observed phenotype, as described below:

$$
y=\left\{\begin{array}{lll}
0 & \text { if } & \lambda<t \\
1 & \text { if } & \lambda>t
\end{array}(t \text { was arbitrarily set to zero }) .\right.
$$

The threshold and the variances were set fixed because the parameters are not identifiable.

The following liability model was used for binary traits:

$$
\begin{aligned}
\lambda_{\mathrm{jklmn}}=\mu & +\mathrm{DFS}_{\mathrm{jklmn}}+\mathbf{L A}_{\mathrm{j}}+\mathbf{M}_{\mathrm{k}}+\mathbf{h} \mathbf{y} \mathbf{r}_{1} \\
& +\mathbf{p}_{\mathrm{m}}+\mathbf{a}_{\mathrm{n}}+\mathrm{e}_{\mathrm{jklmn}}
\end{aligned}
$$

where $\lambda_{j k l m n}$ was the corresponding liability of the observation, $\mathrm{DFS}_{\mathrm{jklmn}}$ was days to first service as covariate, $\mathbf{L} \mathbf{A}_{\mathrm{j}}$ was fixed effect of lactation-age at calving, $\mathbf{M}_{\mathrm{k}}$ was

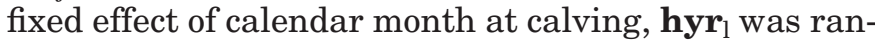
dom effect of herd-year at calving, $\mathbf{p}_{m}$ was random permanent effect, $\mathbf{a}_{\mathrm{n}}$ was animal genetic effect, and $\mathrm{e}_{\mathrm{jklmn}}$ the random residual term.

The herd-year at calving effect was considered random to minimize the disadvantages of reduced size of comparison groups (Moreno et al., 1997). The contemporary groups within herd-year were expanded up to a maximum of $1 \mathrm{yr}$. If any extreme category problems (comparison groups in which every observation falls within the same category) remained, those groups were removed from the data set.

A Bayesian approach was adopted for inferences with Markov chain Monte Carlo sampling used in the binarybinary and linear-binary analyses, integrating the underlying variables by means of a data augmentation algorithm described by Sorensen et al. (1995).

In matrix notation, the models can be represented as:

$$
y=\mathbf{X} \boldsymbol{\beta}+\mathbf{W}_{\mathbf{1}} \boldsymbol{\theta}+\mathbf{W}_{\mathbf{2}} \mathbf{p}+\mathbf{Z} \mathbf{a}+e
$$

where $y$ is the vector of observations (liabilities in case of binary traits), $\boldsymbol{\beta}$ is the vector of systematic effects, $\boldsymbol{\theta}$ is the vector of the herd-year random effect for binary traits, $\mathbf{p}$ is the vector of random permanent effect, $\mathbf{a}$ is a vector of animal effect, and $e$ is a vector of residual effects; $\mathbf{X}, \mathbf{W}_{\mathbf{1}}, \mathbf{W}_{\mathbf{2}}$, and $\mathbf{Z}$ are the corresponding incidence matrices.

Conditionally on the model parameters, it was assumed that the sampling distribution of the observations was:

$$
p(y \mid \beta, \theta, p, a) \sim N\left(\mathbf{X} \boldsymbol{\beta}+\boldsymbol{W}_{\mathbf{1}} \boldsymbol{\theta}+\mathbf{W}_{\mathbf{2}} \mathbf{p}+\mathbf{Z} \mathbf{a}, \mathbf{I} \otimes \mathbf{R}_{\mathbf{0}}\right)
$$

where $\mathbf{R}_{\mathbf{0}}$ is a $2 \times 2$ variance-covariance matrix with the following structure:

$$
\begin{gathered}
\mathbf{R}_{0}=\left[\begin{array}{cc}
\sigma_{e 1}^{2} & \sigma_{e 12} \\
\sigma_{e 12} & \sigma_{e 2}^{2}
\end{array}\right] \text { with } \\
\left\{\begin{array}{l}
\sigma_{e 1}^{2}=1 \text { for binary }- \text { linear analysis } \\
\sigma_{e 1}^{2}=\sigma_{e 2}^{2}=1 \text { for binary }- \text { binary analysis }
\end{array}\right.
\end{gathered}
$$

The residuals were assumed correlated within cows between the 2 simultaneously analyzed traits, and independent between cows.

The posterior conditional distributions for the genetic and permanent (co)variance components were inverted Wishart. Residual (co)variances and herd-year variance (for binary traits) were sampled by Metropolis-Hasting algorithm with a uniform proposal. Flat priors were assumed for the systematic effects.

The joint posterior distribution had the form:

$$
\begin{gathered}
p\left(\boldsymbol{\beta}, \boldsymbol{\theta}, \mathbf{p}, \mathbf{a}, \lambda, \mathbf{R}_{\mathbf{0}}, \mathbf{G}_{\mathbf{0}}, \mathbf{P}_{\mathbf{0}}, \sigma_{\text {hys }}^{2} \mid \mathrm{y}\right) \propto \\
p\left(\mathrm{y} \mid \boldsymbol{\beta}, \boldsymbol{\theta}, \mathbf{p}, \mathbf{a}, \lambda, \mathbf{R}_{\mathbf{0}}, \mathbf{G}_{\mathbf{0}}, \mathbf{P}_{\mathbf{0}}, \sigma_{\text {hys }}^{2}\right) p\left(p \mid \mathbf{P}_{\mathbf{0}}\right) \mathrm{p}\left(\mathbf{a} \mid \mathrm{A}, \mathbf{G}_{\mathbf{0}}\right) \\
p\left(\boldsymbol{\theta} \mid \sigma_{\text {hy }}^{2}\right) p\left(\mathbf{G}_{\mathbf{0}}\right) p\left(\mathbf{R}_{\mathbf{0}}\right) \\
p\left(\mathbf{P}_{\mathbf{0}}\right) p\left(\sigma_{\text {hy }}^{2}\right) .
\end{gathered}
$$

The analyses were implemented using our own software, and the viability of the software was tested by 
simulated data. Each analysis consisted of a single chain of 100,000 iterations, discarding the first 10,000 samples. Burn-in period was determined by the convergence of 2 chains with different initial values. The lag period was 10 samples, having 9000 samples for final inferences. The effective sample size and the Monte Carlo error (Geyer, 1992) of the genetic correlations were estimated for the linear-binary and binary-binary analysis.

\section{Fertility Economic Selection Index}

Index development was based on selection index theory described by Hazel (1943) from discounted economic weights of traits involved in the breeding goals and their genetic relationships with traits included in the index.

Two traits were included in the aggregate genotype: DFS and INS. The economic values reported in a recent study (González-Recio et al., 2004) were used ( $\$ 4.90$ and $-\$ 67.32$ per cow per year for CI and INS, respectively).

The economic value for CI was used for DFS because the relationship between both traits is straightforward. Increasing DFS by $1 \mathrm{~d}$ has the same economic impact as increasing CI by $1 \mathrm{~d}$.

Hence, the aggregate genotype used in the index elaboration was:

$$
H=a_{1} \cdot I N S+a_{2} \cdot D F S
$$

where $\mathrm{H}$ is the aggregate genotype, $a_{1}$ is economic value of INS (-\$67.32), and $a_{2}$ is economic value of DFS $(-\$ 4.90)$.

The selection index is composed of EBV for traits included in the index and their corresponding weights:

$$
F I=\sum_{i=1, n} b_{i} \cdot X_{i}
$$

where FI is the fertility index, $X$ is the EBV for trait $i$ included in the index, and $b_{i}$ is the index weight for trait $i$.

The aggregate genotype and the selection index were related by means of the next equation:

$$
\mathbf{b}=\mathbf{P}^{-1} \mathbf{G a}
$$

where $\mathbf{b}$ is the vector of the index weights, $\mathbf{P}$ is the phenotypic (co)variance matrix of traits (or liabilities in case of binary traits) included in the selection index, $\mathbf{G}$ is the genetic (co)variance matrix between traits in the selection index and traits in the aggregate genotype, and $\mathbf{a}$ is the vector of economic values in the aggregate
Table 1. Number of records, mean, and SD for calving interval (CI), days open (DO), cow pregnancy rate (PR), interval from first to last insemination (IFL), days to first insemination (DFS), number of inseminations per service period (INS), pregnancy within 56 (P56) and 90 (P90) days after first insemination, and percentage of success at first insemination (SF).

\begin{tabular}{lccc}
\hline Trait & No. & Mean & SD \\
\hline CI (d) & 96,346 & 400 & 60.0 \\
DO (d) & 113,375 & 117 & 57.1 \\
PR (\%) & 113,375 & 29 & 14 \\
IFL (d) & 113,375 & 36 & 52 \\
DFS (d) & 120,713 & 81 & 27.7 \\
INS & 113,375 & 1.87 & 1.18 \\
P56 (\%) & 69,833 & 72 & $0.17^{1}$ \\
P90 (\%) & 69,833 & 83 & $0.14^{1}$ \\
SF (\%) & 69,833 & 49 & $0.19^{1}$ \\
\hline
\end{tabular}

${ }^{1}$ Mean standard error instead of standard deviation, because binary traits are recorded only as 0 or 1.

genotype. Correlated genetic response was computed as $C_{R}=\frac{\mathbf{b}^{\prime} \mathbf{G}}{\sqrt{\mathbf{b}^{\prime} \mathbf{P b}}}$, implying selection intensity equals one.

A set of fertility selection indices were developed based on (co)variance results of this study.

\section{RESULTS AND DISCUSSION}

\section{Genetic Parameters}

Table 1 presents a descriptive summary of the edited data used in the present study. The editing process reduced the original data set to $40 \%$. Table 2 shows heritabilities (in the observed scale for linear traits and in the liability scale for binary traits), and phenotypic and genetic correlations among fertility traits. Low heritabilities (0.02 to 0.06) were estimated, according to literature (Dematawewa and Berger, 1998; Veerkamp et al., 2001). In general, genetic correlations were high (0.89 to 0.99) except for DFS, for which correlations were -0.52 with SF, 0.82 with DO, and -0.82 with PR. Binary traits (P56, P90, and SF) had high positive genetic correlations among them (from 0.92 to 0.97 ) and negative correlations with remaining traits (from -0.18 for SF-DFS to -0.95 for P56-CI, P56-DO, and P90-CI). The P56 showed stronger correlation $(-0.90)$ with INS than P90 (-0.54), suggesting that P56 is a more suitable indicator of pregnancy rate when INS cannot be recorded. Calving interval, DO, and PR had genetic correlations near 1.00 ( -1.00 for $\mathrm{PR}$ ) with each other, because they represent the same trait. Days open can be calculated as CI minus gestation period, and PR is a linear function of DO. These 3 interval traits can be obtained from a milk recording scheme. Analyzing one of them would be sufficient, because the remaining 2 contribute no additional information. Heterogeneous correlations between DFS and other traits support the inclusion of 
Table 2. Heritabilities (diagonal, in bold), genetic (above diagonal), and phenotypic (below diagonal) correlations among fertility traits ${ }^{1}$ with standard errors ${ }^{2}$ in parentheses.

\begin{tabular}{|c|c|c|c|c|c|c|c|c|c|}
\hline & CI & DO & PR & IFL & DFS & INS & P56 & P90 & $\mathrm{SF}$ \\
\hline CI & 0.04 & $0.99_{(0.01)}$ & $-0.99_{(0.01)}$ & $0.98_{(0.01)}$ & $0.80_{(0.03)}$ & $0.89_{(0.02)}$ & $-0.95_{(0.002)}$ & $-0.95_{(0.001)}$ & $-0.59_{(0 . c}$ \\
\hline DO & 0.91 & 0.04 & $-0.99_{(0.01)}$ & $0.99_{(0.01)}$ & $0.82_{(0.03)}$ & $0.94_{(0.01)}$ & $-0.95_{(0.001)}$ & $-0.93_{(0.02)}$ & $-0.94_{(0.002)}$ \\
\hline PR & -0.91 & -1.00 & 0.04 & $-0.99_{(0.01)}$ & $-0.82_{(0.03)}$ & $-0.94_{(0.01)}$ & $0.95_{(0.001)}$ & $0.93_{(0.02)}$ & $0.94_{(0.002)}$ \\
\hline IFL & 0.79 & 0.88 & -0.88 & 0.03 & $0.50_{(0.05)}$ & $0.91_{(0.02)}$ & & & \\
\hline DFS & 0.38 & 0.42 & -0.42 & -0.07 & 0.05 & $0.11_{(0.06)}$ & $-0.44_{(0.03)}$ & $-0.18_{(0.02)}$ & $-0.52_{(0.03)}$ \\
\hline INS & 0.68 & 0.75 & -0.75 & 0.87 & -0.08 & 0.02 & $-0.90_{(0.01)}$ & $-0.54_{(0.03)}$ & \\
\hline P56 & -0.64 & -0.75 & 0.75 & -0.85 & 0.04 & -0.75 & 0.05 & $0.97_{(0.02)}$ & $0.94_{(0.0}$ \\
\hline P90 & -0.59 & -0.74 & 0.74 & -0.84 & 0.03 & -0.69 & 0.76 & 0.06 & $0.92_{(0.02)}$ \\
\hline $\mathrm{SF}$ & -0.54 & -0.61 & 0.61 & -0.71 & 0.06 & -0.76 & 0.63 & 0.48 & 0.04 \\
\hline
\end{tabular}

${ }^{1} \mathrm{CI}=$ Calving interval, $\mathrm{DO}=$ days open, $\mathrm{PR}=$ pregnancy rate, $\mathrm{IFL}=$ interval between first and last inseminations, DFS = days to first service, $\mathrm{INS}=$ number of inseminations per service period, $\mathrm{P}=$ pregnancy within 56 (P56) or $90 \mathrm{~d}$ (P90) after first insemination, $\mathrm{SF}=$ success in first insemination.

${ }^{2}$ Monte Carlo error for Bayesian analysis for linear-binary traits. Estimates for binary traits are in the liability scale. Standard errors ranged from 0.002 to 0.003 for heritability estimates and were $<0.0001$ for phenotypic correlation estimates.

this trait in a fertility index. Days open (or PR), IFL, and P56 were the most highly correlated traits with INS, suggesting their suitability as substitutes for INS in a selection index, because INS requires a higher quality recording scheme.

In general, these results agree with low heritabilities and strong genetic correlations estimated by other researchers. Recent studies, such as those of Kadarmideen et al. (2003) and Veerkamp et al. (2001) reported strong (positive and negative) correlations, ranging from \pm 0.70 to \pm 0.98 for fertility traits (except for DFS, which were moderate). Weigel and Rekaya (2000) estimated a product-moment correlation of sire EBV for female fertility of 0.98 between nonreturn rate at 60 and $90 \mathrm{~d}$ using threshold methodology and animal model in herds from California and Minnesota. However, Wall et al. (2003) reported lower correlations $(0.61$ and -0.45$)$ for CI with INS and nonreturn rate at $56 \mathrm{~d}$, respectively. Kadarmideen et al. (2000), using a threshold sire model, estimated similar heritabilities for binary traits, and Averill et al. (2004) reported a heritability of 0.028 for female fertility using longitudinal binary data with Bayesian methodology. Comparison between P56 (or P90) with nonreturn rates must be considered carefully because nonreturn rates indicate no presence of an additional AI within a given period; meanwhile P56 (P90) indicates pregnancy within $56 \mathrm{~d}(90 \mathrm{~d})$ (achieved with any number of AI) after first insemination. It means that success for P56 and P90 can be achieved with any number of inseminations, whereas only one $\mathrm{AI}$ is considered in the nonreturn rate. Hence, this comparison must be considered carefully.

In view of these results, 3 groups of fertility traits can be defined. The first group would include DFS as an indicator of the time that a cow needs to get ready to be inseminated. It should be noted that a problem arises with such a trait when heat synchronization is practiced (which is not the case in the studied population). This group could include other traits, such as heat strength or hormone concentrations in milk (Royal et al., 2002); these traits were not included in this study but could be considered in future research. The second group would include traits that indicate pregnancy rate, such as INS (preferable), IFL, P56, and P90. Finally, the last group would include traits that are composite measures of time to first insemination and pregnancy rate, such as CI, DO, and PR. However, it is not recommended to consider these traits for selection unless group 1 and 2 traits are unavailable. Calving interval, DO, and PR cannot distinguish between infertility due to a delay in reproductive performance or due to low success rate of AI events. Moreover, these traits are influenced by management practices and voluntary extension of lactations.

Sample size and highest probability density interval (95\%) for genetic correlations were calculated for every bivariate Bayesian analysis (Table 3). The highest probability interval was set as the interval that contained $95 \%$ of the total samples. Sample size ranged from 6 (P90-DFS) to 141 (P56-DO and P56-PR). Although small sample sizes were obtained, the Monte Carlo error was always less than 0.03. Larger genetic correlations had smaller highest probability intervals. Analyses with small sample size could require longer Markov chains. Moderate genetic correlation (between $\mathrm{SF}$ and CI, P56 and DFS, P90 and DFS, and P90 and INS) had wider highest probability intervals.

Genetic correlations from bivariate analysis of P56 and P90 with IFL, and SF with IFL and INS could not be estimated. If the first insemination was successful, the phenotypic values corresponding to binary traits are 1 , and the phenotypic value for IFL is always 0 . Also, a phenotypic value of 1 for INS corresponds to a phenotypic value of 1 for SF. Therefore, residual and 
Table 3. Sample size (SS) and highest probability density 95\% (HPD) for genetic correlation estimates in binary-linear and binary-binary analysis of fertility traits. ${ }^{1}$

\begin{tabular}{|c|c|c|c|c|c|c|c|c|}
\hline & & CI & DO & PR & DFS & INS & P90 & $\mathrm{SF}$ \\
\hline P56 & HPD & $-0.98,-0.92$ & $-0.97,-0.93$ & $0.93,0.97$ & $-0.59,-0.22$ & $-0.95,-0.84$ & $0.95,0.99$ & $0.92,0.97$ \\
\hline P90 & SS & 104 & 15 & 15 & 6 & 27 & $\ldots$ & 20 \\
\hline \multirow[t]{2}{*}{ SF } & SS & 30 & 86 & 86 & 26 & $\ldots$ & $\ldots$ & $\ldots$ \\
\hline & HPD & $-0.66,-0.53$ & $-0.98,-0.93$ & $0.93,0.98$ & $-0.27,-0.08$ & $\ldots$ & $\ldots$ & $\ldots$ \\
\hline
\end{tabular}

${ }^{1} \mathrm{CI}=$ Calving interval, $\mathrm{DO}=$ days open, $\mathrm{PR}=$ pregnancy rate, DFS = days to first service, INS = number of inseminations per service period, $\mathrm{P}=$ pregnancy within 56 (P56) or $90 \mathrm{~d}$ (P90) after first insemination, $\mathrm{SF}=$ success in first insemination.

genetic correlations tended to 1 and nonconvergence was reached, leading to severe bias. Few studies show genetic correlation estimations among these traits. However, Kadarmideen et al. (2003) estimated a correlation of -0.92 between INS and SF using a linear animal model, but due to the binary nature of SF, P56, and P90, a linear model could lead to severe bias. An alternate way to recode those traits should be studied to estimate their respective correlations.

\section{Fertility Economic Selection Index}

Six fertility selection indices were proposed based on estimated (co)variances in this study. The first 2 fertility indices $\left(\mathrm{FI}_{1}\right.$ and $\left.\mathrm{FI}_{2}\right)$ were calculated with only information from milk recording scheme (CI and PR, respectively).

$$
\begin{aligned}
& F I_{1}=b_{11} C I \\
& F I_{2}=b_{21} P R
\end{aligned}
$$

Days to first service, indicating time from calving to the beginning of the reproductive performance, and another trait related to pregnancy rate (INS, IFL, P56, and P90) were selected to develop the rest of indices. The third index $\left(\mathrm{FI}_{3}\right)$ included DFS and interval from first to last insemination: IFL.

$$
F I_{3}=b_{31} D F S+b_{32} I F L
$$

The fourth and fifth indices $\left(\mathrm{FI}_{4}\right.$ and $\mathrm{FI}_{5}$ ) were calculated following the recommendations from Groen et al. (1998), who concluded that every country should analyze, at minimum, DFS and nonreturn rate.

$$
\begin{aligned}
& F I_{4}=b_{41} D F S+b_{42} P 56 \\
& F I_{5}=b_{51} D F S+b_{52} P 90
\end{aligned}
$$

Finally, a fertility index $\left(\mathrm{FI}_{6}\right)$ was calculated including DFS and INS.

$$
F I_{6}=b_{61} D F S+b_{62} I N S
$$

Insemination data are necessary for indices $\mathrm{FI}_{3}, \mathrm{FI}_{4}$, $\mathrm{FI}_{5}$, and $\mathrm{FI}_{6}$.

Table 4 presents the Spearman correlation among the 6 fertility indices and the EBV for breeding goal traits of sires with more than 25 daughters. Table 5 shows weights for each index and the genetic gain for the breeding goals (DFS and INS). All fertility indices had correlations over 0.80 , and their correlations with INS EBV were quite similar (0.61 to 0.90). However, the $\mathrm{FI}_{4}$ and $\mathrm{FI}_{5}$ were less correlated to DFS EBV (0.38 and 0.44 ). When data from the milk recording scheme was the only available information, the indices $\mathrm{FI}_{1}$ and $\mathrm{FI}_{2}$ (based on $\mathrm{CI}$ and $\mathrm{PR}$ ) had an expected genetic gain of $\$ 6.93$ and $\$ 7.47$, respectively, per generation and unit of selection intensity (Table 5). It is recommended to use linear transformation of DO (PR) instead of CI to reduce fertility cost, because economic genetic gain is higher for PR. Although Spearman correlations were high for $\mathrm{FI}_{1}$ and $\mathrm{FI}_{2}$ with $\mathrm{EBV}$ for breeding goal traits (Table 4 ), at least $15 \%$ of genetic gain could be increased with indices that include reproductive information (DFS and P56). Similar genetic gains were estimated with all indices ( $\$ 6.93$ to $\$ 7.90$ ), but higher genetic gain could be obtained with an index composed of DFS and P56 (\$8.60).

Genetic gains are expressed assuming the same generation intervals for all indices. However, it should be noted that considering proper generation intervals would lead to lower expected genetic gain for fertility using indices that include CI or DO (as PR), because these traits cannot be calculated until second lactation. In addition, selection intensity equal to one was considered. Usually, higher selection intensity is applied in field when considering 4 paths in dairy cattle, which would lead to higher genetic gains than the ones reported here, but this would not change the conclusions of the study.

These results suggest that selection for fertility should focus on DFS as a trait to indicate beginning of reproductive performance and P56 as a trait to indicate conception rate and an early successful insemination. Such a fertility index would have a relevant influence on genetic gain for reduced fertility costs. 
Table 4. Spearman correlations among fertility indices (FI) and with EBV for breeding goal traits days to first service (DFS) and number of inseminations per service period (INS) for sires with more than 25 daughters (standard errors $<0.0001$ ).

\begin{tabular}{|c|c|c|c|c|c|c|c|c|}
\hline & $\mathrm{FI}_{1}$ & $\mathrm{FI}_{2}$ & $\mathrm{FI}_{3}$ & $\mathrm{FI}_{4}$ & $\mathrm{FI}_{5}$ & $\mathrm{FI}_{6}$ & $\mathrm{DFS}_{\mathrm{EBV}}$ & $\mathrm{INS}_{\mathrm{EBV}}$ \\
\hline $\mathrm{FI}_{1}$ & . & 0.91 & 0.88 & 0.83 & 0.81 & 0.80 & -0.71 & -0.86 \\
\hline $\mathrm{FI}_{2}$ & & $\ldots$ & 0.87 & 0.83 & 0.80 & 0.80 & -0.70 & -0.91 \\
\hline $\mathrm{FI}_{3}$ & & & $\ldots$ & 0.87 & 0.88 & 0.98 & -0.94 & -0.77 \\
\hline $\mathrm{FI}_{4}$ & & & & $\ldots$ & 0.96 & 0.84 & -0.44 & -0.73 \\
\hline $\mathrm{FI}_{5}$ & & & & & $\ldots$ & 0.85 & -0.38 & -0.65 \\
\hline $\mathrm{FI}_{6}$ & & & & & & $\ldots$ & -0.98 & -0.70 \\
\hline
\end{tabular}

This fertility index is similar to that proposed in Switzerland, which includes DFS and nonreturn rate at 56 $\mathrm{d}$ after first insemination (Interbull, 2004). The fertility index in Finland is based on days open (66\%) and fertility treatments $(33 \%)$. Daughter pregnancy rate computes $7 \%$ in the US Net Merit Index, and Canada includes DFS (22\%) and cow nonreturn rate (13\%) in the herd life index (CDN, 2005).

\section{Insemination Recording Scheme Benefits}

The results of this study indicate the usefulness of recording insemination data within a dairy population. Although traits from milk recording scheme (DO and CI) can be calculated for the whole dairy population, thereby increasing EBV accuracy, they had other drawbacks such that they cannot properly predict female fertility, and they cannot be calculated until second lactation (thereby increasing generation interval). However, DFS and P56 can be recorded at the beginning of the first lactation, reducing generation interval when compared with DO (PR) or CI. In addition, a fertility index based on DFS and P56 increased genetic gain by $15 \%$ when compared with fertility indices using data from milk recording schemes. Pregnancy within $56 \mathrm{~d}$ after first insemination would be preferable to P90, because it was more highly correlated with INS and could achieve higher genetic gain in profit. Recording the date of the first insemination and checking pregnancy by $56 \mathrm{~d}$ is recommended. Although slow genetic progress is expected, a proper insemination recording scheme could supply information about farm reproductive performance that could be used to improve female fertility phenotypically as well. In addition, male fertility can be analyzed if service sire is recorded. Male fertility data are growing in importance to farms and AI studs (Averill et al., 2004; DeJarnette et al., 2004). It should be noted that populations that do not register AI events could reduce fertility cost in an efficient way by selection on DO or CI.

\section{CONCLUSIONS}

Female fertility traits can be classified into 3 groups. First are measures of the beginning of the service period (DFS). Second are conception rate traits (IFL, INS, P56, and P90), which are strongly correlated with each other. Third are traits from milk recording schemes (CI, DO, and PR) that should be used to measure female fertility only when the remaining fertility traits are not available. These traits cannot distinguish delays in beginning the service period and a low success of AI events.

Genetic progress in fertility requires a long time due to low heritabilities, but fastest improvement for female

Table 5. Index weights and genetic gain on breeding goal traits days to first service (DFS), number of inseminations per service period (INS), and US dollars for each considered selection index.

\begin{tabular}{|c|c|c|c|c|c|}
\hline \multirow[b]{2}{*}{ Fertility index ${ }^{2}$} & \multirow[b]{2}{*}{ Index weight } & \multirow[b]{2}{*}{ Index weight (\%) } & \multicolumn{3}{|c|}{ Expected genetic gain $^{1}$} \\
\hline & & & DFS (d) & INS & $\$$ \\
\hline $\mathrm{FI}_{1}=\mathrm{PR}$ & $0.23 \mathrm{PR}$ & $100 \mathrm{PR}$ & -0.97 & -0.04 & 7.47 \\
\hline $\mathrm{FI}_{2}=\mathrm{CI}$ & $-0.05 \mathrm{CI}$ & $-100 \mathrm{CI}$ & -0.95 & -0.03 & 6.93 \\
\hline $\mathrm{FI}_{3}=\mathrm{DFS}+\mathrm{IFL}$ & $-0.11 \mathrm{DFS}-0.04 \mathrm{IFL}$ & -62 DFS -38 IFL & -1.36 & -0.02 & 7.79 \\
\hline $\mathrm{FI}_{4}=\mathrm{DFS}+\mathrm{P} 56$ & $-0.11 \mathrm{DFS}+2.61 \mathrm{P} 56$ & $-52 \mathrm{DFS}+48 \mathrm{P} 56$ & -1.31 & -0.03 & 8.60 \\
\hline $\mathrm{FI}_{5}=\mathrm{DFS}+\mathrm{P} 90$ & -0.11 DFS +2.05 P90 & $-58 \mathrm{DFS}+42 \mathrm{P} 90$ & -1.37 & -0.02 & 7.90 \\
\hline $\mathrm{FI}_{6}=\mathrm{DFS}+\mathrm{INS}$ & $-0.11 \mathrm{DFS}-1.05 \mathrm{INS}$ & -71 DFS - 29 INS & -1.26 & -0.01 & 7.09 \\
\hline
\end{tabular}

\footnotetext{
${ }^{1}$ Genetic gain calculated assuming selection intensity of one and the same generation interval for every trait.

${ }^{2} \mathrm{CI}=$ Calving interval, $\mathrm{PR}=$ pregnancy rate, DFS $=$ days to first service, $\mathrm{IFL}=$ interval between first and last insemination, INS = number of inseminations per service period, $\mathrm{P}=$ pregnancy within $56(\mathrm{P} 56)$ or $90 \mathrm{~d}$ (P90) after first insemination.
} 
fertility is reached with DFS, as a trait to indicate beginning of reproductive performance, and $\mathrm{P} 56$, as a trait to measure conception rate. A fertility index with those traits would lead to improvement of $-1.31 \mathrm{~d}$ to first insemination, and reduce inseminations per lactation by -0.03 , per generation assuming one unit of selection intensity. Profit would increase by $\$ 8.60$ per cow per generation. If no reproductive records are available, a fertility index should include DO (or PR) as the fertility trait, but female fertility cannot be predicted properly, and expected genetic gain will be reduced.

Genetic correlations between linear-binary and binary-binary traits suggest that an animal model can be implemented when proper data structure is achieved through extended or random contemporary group effects. Using an animal model would increase accuracy of binary trait EBV.

\section{ACKNOWLEDGMENTS}

The authors wish to express their appreciation to Dr. García-Cortés for his helpful assistance with the Bayesian methodology, and to Drs. Weigel, Chang, and Gianola, as well as 2 anonymous reviewers, for their useful comments and suggestions.

\section{REFERENCES}

Averill, T. A., R. Rekaya, and K. Weigel. 2004. Genetic analysis of male and female fertility using longitudinal binary data. J. Dairy Sci. 87:3947-3952.

CDN. 2005. Canadian Dairy Network. Online. Available http:// www.cdn.ca/articles/0411/IndirectHerdLife.pdf. Accessed Feb. $3,2005$.

DeJarnette, J. M., C. E. Marshall, R. W. Lenz, and D. R. Monke. 2004. Sustaining the fertility of artificially inseminated dairy cattle: The role of the artificial insemination industry. J. Dairy Sci. 87(E. Suppl.):E93-E104.

De Jong, G., and A. G. F. Harbers. 2001. The effect of more health traits in DPS on economic selection. Interbull Bull. 27:97-101.

Dematawewa, C. M. B., and P. J. Berger. 1998. Genetic and phenotypic parameters for 305-day yield, fertility, and survival in Holstein. J. Dairy Sci. 81:2700-2709.

Geyer, C. J. 1992. Practical Markov chain Monte Carlo. Stat. Sci. $7: 473-511$

Gianola, D. 1982. Theory and analysis of threshold characters. J. Anim. Sci. 54:1079-1096.
González-Recio, O., M. A. Pérez-Cabal, and R. Alenda. 2004. Economic value of female fertility and its relationship with profit in Spanish Dairy Cattle J. Dairy Sci. 87:3053-3061.

Groen, A. F., J. Sölkner, J. Aumann, V. Ducrocq, N. Gengler, and E. Strandberg. 1998. EU Concerted Action "Genetic Improvement of Functional Traits in Cattle". Interbull Bull. 19:9-20.

Groen, A. F., T. Steine, J. J. Colleau, J. Pedersen, J. Pribyl, and N. Reinsch. 1997. Economic values in dairy cattle breeding, with special reference to functional traits. Report of EAAP-working group. Livest. Prod. Sci. 49:1-21.

Groeneveld, E., and L. A. García-Cortés. 1998. VCE 4.0, a (co)variance component package for frequentists and Bayesians. Proc. 6th. World Congr. Genet. Appl. Livest. Prod. 27:455-456.

Hazel, L. N. 1943. The genetic basis for constructing selection indices. Genetics 28:476-490.

Hoeschele, I., and B. Tier. 1995. Estimation of variance components of threshold characters by marginal posterior modes and means via Gibbs sampling. Genet. Sel. Evol. 27:519-540.

Interbull. 2004. National GES information. Online. Available http:// www-interbull.slu.se/national_ges_info2/framesida-ges.htm. Accessed Nov. 14, 2004.

Kadarmideen, H. N., R. Thompson, M. P. Coffey, and M. A. Kossaibati. 2003. Genetic parameters and evaluations from single- and multiple-trait analysis of dairy cow fertility and milk production. Livest. Prod. Sci. 81:183-195.

Kadarmideen, H. N., R. Thompson, and G. Simm. 2000. Linear and threshold model genetic parameters for disease, fertility, and milk production in dairy cattle. Anim. Sci. 71:411-419.

Kuhn, M. T., P. M. VanRaden, and J. L. Hutchison. 2004. Use of early lactation days open records for genetic evaluation of cow fertility. J. Dairy Sci. 87:2277-2284.

Moreno, C., D. Sorensen, L. A. García-Cortes, L. Varona, and J. Altarriba. 1997. On biased inferences about variances components in the binary threshold model. Genet. Sel. Evol. 29:145-160.

Pryce, J. E., M. D. Royal, P. C. Garnsworthy, and I. L. Mao. 2004. Fertility in the high-producing cows. Livest. Prod. Sci. 86:125135.

Royal, M. D., A. P. F. Flint, and J. A. Woolliams. 2002. Genetic and phenotypic relationships among endocrine and traditional fertility traits and production traits in Holstein-Friesian dairy cows. J. Dairy Sci. 85:958-967.

Sorensen, D., S. Andersen, D. Gianola, and I. Korsgaad. 1995. Bayesian inference in threshold model using Gibbs sampling. Genet. Sel. Evol. 27:229-249.

Thompson, R. 1979. Sire evaluation. Biometrics 35:339-353.

Ugarte, E., R. Alenda, and M. J. Carabaño. 1992. Fixed or random contemporary groups in genetic evaluations. J. Dairy Sci. 75:269-278.

Veerkamp, R. F., E. P. C. Koenen, and G. De Jong. 2001. Genetic correlations among body condition score, yield, and fertility in first-parity cows estimated by random regression models. J. Dairy Sci. 84:2327-2335.

Wall, E., V. E. Olori, M. P. Coffey, and S. Brotherstone. 2003. Prediction of UK fertility proofs for foreign bulls. Interbull Bull. 31:60-64.

Weigel, K. A., and R. Rekaya. 2000. Genetic parameters for reproductive traits of Holstein cattle in California and Minnesota. J. Dairy Sci. 83:1072-1080. 